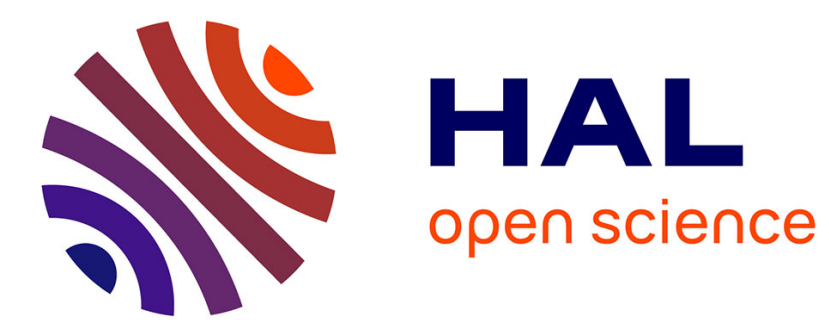

\title{
Collective Intelligence and Collaboration: A Case Study in Airline Industry
}

Sónia Teixeira, Pedro Campos, Renato Fernandes, Catarina Roseira

\section{To cite this version:}

Sónia Teixeira, Pedro Campos, Renato Fernandes, Catarina Roseira. Collective Intelligence and Collaboration: A Case Study in Airline Industry. 17th Working Conference on Virtual Enterprises (PRO-VE), Oct 2016, Porto, Portugal. pp.148-155, 10.1007/978-3-319-45390-3_13 . hal-01614596

\author{
HAL Id: hal-01614596 \\ https://hal.inria.fr/hal-01614596
}

Submitted on 11 Oct 2017

HAL is a multi-disciplinary open access archive for the deposit and dissemination of scientific research documents, whether they are published or not. The documents may come from teaching and research institutions in France or abroad, or from public or private research centers.
L'archive ouverte pluridisciplinaire HAL, est destinée au dépôt et à la diffusion de documents scientifiques de niveau recherche, publiés ou non, émanant des établissements d'enseignement et de recherche français ou étrangers, des laboratoires publics ou privés.

\section{(c)(1)}

Distributed under a Creative Commons Attribution| 4.0 International License 


\title{
Collective Intelligence and Collaboration: A Case Study in Airline Industry
}

\author{
Sónia A.C. Teixeira ${ }^{1,2}$, Pedro Campos ${ }^{1,2}$, Catarina Roseira ${ }^{2}$, Renato Fernandes ${ }^{1,2}$ \\ ${ }^{1}$ Faculty of Economics, University of Porto, Portugal \\ \{pcampos, croseira\}@fep.up.pt \\ ${ }^{2}$ INESC Technology and Science, Porto, Portugal \\ \{sonia.c.teixeira, renato.s.fernandes\}@inesctec.pt
}

\begin{abstract}
In order to improve their competitive performance, airline companies often adopt as a strategy to establish arrangement between two or more organizations agreeing to cooperate on a substantial level. This strategy is often known as airline alliances. A paradigm to analyze the collective intelligence behavior which emerges from a group, as a strategic alliance, is the flocking behavior. Inspired by the Cucker and Smale algorithm (C-S) we propose a new version of the flocking behavior algorithm applied to airline alliances. Our goal is to understand the link between strategic alliances and flocks. For this new approach, metrics were obtained for the parameters of C-S algorithm, namely position, velocity and influence, where the latter uses cooperative games. Besides, reinforcement learning mechanisms have been explored. Some relevant outputs for airline alliances as the permanence rate and the growth rate were computed for each of the five configurations in analysis.
\end{abstract}

Keywords. Collective Intelligence, Airline Industry, Flocking Behavior

\section{Introduction}

The evolution of markets induces a change in the way organizations act. Collaboration between organizations, as an alternative or in parallel to competition, allows them to get the edge over other competitors or potential new organizations of the same market [8]. In this work, we focus on airline industry and explore the emerging collective intelligence and collaboration in the perspective of flocking behavior. The nature of airline industry is different from other industries because it requires public reassurances and operating procedures that include a governmental involvement, which implicitly encourages collaborative working practices [5]. Collaboration in airline industry allows organizations to reduce costs from sharing operational staff, making investments or negotiating extra volume discounts, what can represent lower prices due to lowered operational costs for a given route. In that way, organizations increase revenue and generate opportunities. What derives from the shared belief that together the network members can achieve goals that would not be possible or would have a higher cost if they try to achieve individually [2]. Social dynamics factors are 
important to understand fundamental economic questions, which can be compromised when social preferences are not taken into account, because it is not possible to understand adequately the laws that govern cooperation and collective action, or the effects and the determinants of material incentives or even the important forces which shaping social norms and market failures [6]. The algorithms of flocking behavior [3], [4], [10], [12], [16], are methods that use simple rules to describe the evolution of a flock and are appropriate to simulate the behavior of a group of organizations, such as airline alliances, that move in accordance to a common goal. We propose a new version of the flocking behavior of Cucker and Smale (C-S) algorithm [4] applied to airline alliances, taking into account a learning mechanism. The model is named AllFlock and the goal is to understand the link between strategic alliances and flocking behavior. The permanence rate of the alliances (computed for simulated and real data) and the growth rate of the alliances were computed for each of the five configurations in analysis, which can be important to evaluate the fitness and the structure of the alliance. The paper is organized as follows: In Section 2 we introduce collective intelligence, swarm intelligence and flocking behavior algorithms. Our case study in airline industry is described in Section 3. In Section 4 results are presented and finally Section 5 presents the conclusion.

\section{Collective Intelligence, Swarm Intelligence and Flocking Behavior Algorithms}

The terminology used by Saminen in [13] mentions swarm intelligence to refer to emergent collective behavior in simple agents. On another hand, collective intelligence in humans is a relatively new and multidisciplinary subject. Since the appearance of the name of collective intelligence many other approaches arose, as purely theoretical, conceptual, for simulations, case studies, experiences and systems architecture [13]. Areas such as psychology, complexity, cognitive studies, biology, computer science and the media also gave their contribution to this multidisciplinary theme [13]. Swarms algorithms [1] are based on social and collective behavior that is observed in ants, birds, insects, etc. Ant colony optimization (ACO), particle swarm optimization (PSO), as well as self-propelled particles algorithms (SPP) [16], are part of the class of swarm intelligence algorithms. The term self-propelled particles arises when flocking algorithm proposed by Vicsek et al. in [16], which describe a group of particles, each them which acts as an autonomous agent and each follows same simple rules as a way to regulate their behavior. The intelligence of these same systems are triggered by the collective behavior of individuals, that is, interactions between individuals lead to the emergence of a global intelligent behavior, named collective intelligence [9]. The flocking has been seen to Olfati-Saber [10], as "a form of collective behavior of a large number of agents that interact with a common group goal". This complex movement caught the attention of Reynolds, also, who in 1987 proposed a simulation-based approach to the flock movement [12]. This movement, very similar to a natural flock, is created by a distributed behavioral model in which each bird acts as an independent agent and chooses its course. The flocking behavior is the result of 
the interaction of simple behaviors of agents, represented by rules. The starting point for the Cucker and Smale (C-S) model [4], one of the most important algorithms of flocking, arises from an extension of a work by the same authors [3], in which an analysis is made to the flocking model from Vicsek et al. [16]. Motivation for such extension was the observation that under certain initial conditions of the state the flock converge, ie all birds fly at the same velocity. The proposed development model [4], uses three important parameters namely: position, velocity and influence and aims at searching for the conditions for the state under which the convergence is established. We propose an innovative extension of the flocking algorithm of [4] where position is viewed as the choice of potential partner organization, velocity is the performance of the organization when compared to the alliance (measured as the growth of the net income between two time steps) and influence is measured through the Shapley Value [11], [14], with the aim of dividing goods gained by the cooperation among many organizations. We also consider that organizations learn through interactions within the alliances where they belong. Reinforcement learning [15] is the method we use to implement the learning mechanism in the flocking behavior. The permanence rate and the growth rate of the alliances were computed by each of the five configurations in analysis. The permanence rate was also computed for simulated and real data, by each alliance.

\section{Case Study: AllFlock Applied to Airline Industry}

Until September 2015, there were mainly three alliances in airline industry: SkyTeam (founded in 2000, with 20 members), Oneworld (founded in 1999, containing 15 members) and StarAlliance (1997, with 27 members). A new alliance, Vanilla Alliance started in September 2015, and U-FLY Alliance in January 2016, with 5 and 4 members respectively. Some annual results from three biggest airlines alliances are presented at Table 1.

Table 1. Results from StarAlliance, SkyTeam, Oneworld (adapted from Oneworld site, SkyTeam and StarAlliance annual report 2015)

\begin{tabular}{lccc}
\hline & StarAlliance & SkyTeam & Oneworld \\
\hline Passengers (million) & 641.10 & 612 & 512.6 \\
Countries & 192 & 177 & 154 \\
Employees & 432603 & 481691 & 389788 \\
Total Revenue (US millions) & 179.05 & 186.331 & 141.404 \\
Daily departures & 18500 & 16323 & 14313 \\
\hline
\end{tabular}

Airline industry growing business, in terms of market prospects, once the traffic has been duplicating every 15 years. The AllFlock model (Flocking in Strategic Alliances) proposed in this paper intends to recreate the way as organizations act in order to analyze it in terms of flocking behavior. AllFlock models the intragroup behavior where each agent knows the decisions of the other agents (companies) belonging to the same alliance. There are two important decisions: 1) What company to follow 
(based on a combination of the utility function - Choice - and the Growth; 2) The decision of remaining in the alliance (based on Shapley value and the Growth). The pseudocode of ALLFlock is presented in the following lines.

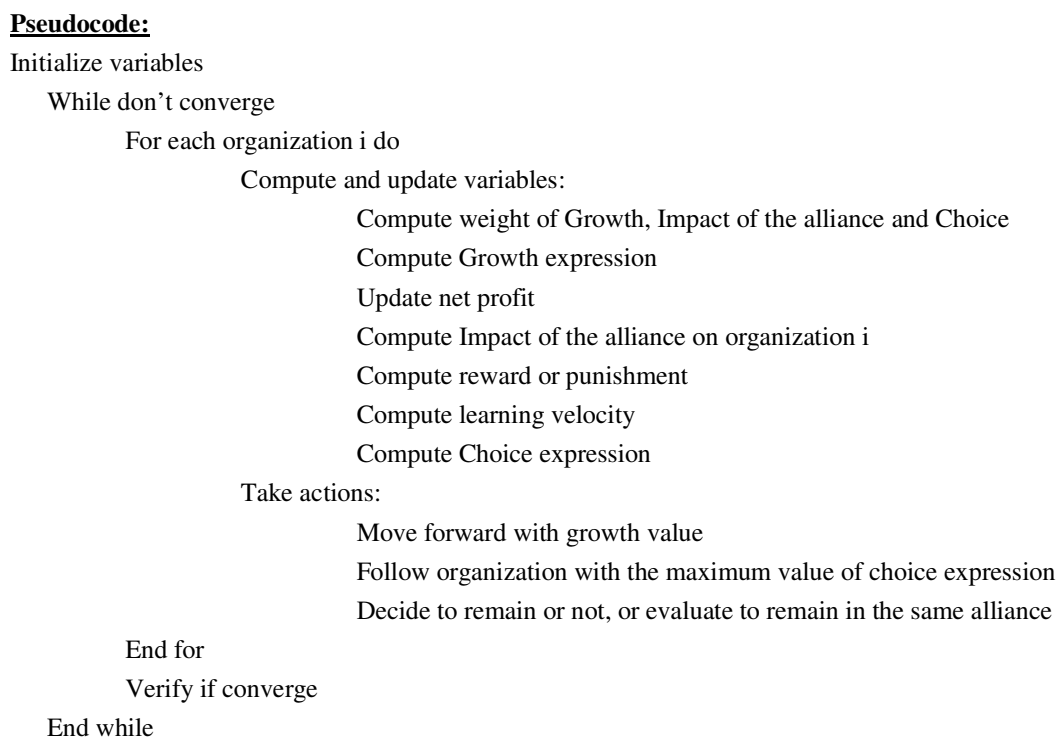

The velocity in C-S is represented by the performance of an organization relative to the performance of alliance. Influence is measured by how much the organization considers to win with a specific alliance, which is the impact of a coalition could have on the organization. This is considered regardless of their physical location, unlike CS. Simply put, each organization has to choose another organization to follow in each instant $\mathrm{t}$, and this choice is dependent of growth, choice and influence (impact) of the alliance in previous moments. Regarding the position, we assume implicitly that organizations choose to collaborate with other organizations in order to maximize the gains. Following that idea, we compute choice value the result of tendencies by particular organizations. The AllFlock model considers that depending on their aspirations, at every time $t$, organizations give different importance to these three aspects. For that reason we included $p e_{i}(t), p s_{i}(t)$ e $p c_{i}(t)$, as the weights with which organization $i$ attaches choice, influence and growth, respectively. Choice considers which organization $j$ the organization $i$ wants to follow as a potential partner. When organization $i$ is looking for the best direction to go, which means the organization that maximizes the choice expression, it collects information throughout their interactions in respect of previous choices. In our view, organization $i$ is learning by trial and error, which is common in reinforcement learning situations. Collaboration is also taken into account in the reinforcement learning, where each company gives rewards or punishments to other companies for their attunement with choices. Let us denote the velocity at which the agent assimilates information by $\alpha, r$ the reward and the amorti- 
zation rate by $\gamma$ (the latter being defined by the user. Therefore, denoting by $E_{i j}(t)$, the choice, at time $t$; the influence of the alliance is $S_{i}(t)$, and the growth of the organization $i$ at time $t$ is $C_{i}(t)$, we have:

$E_{i j}(t+\Delta t)=(1-\alpha) *\left(E_{i j}(t) * p e_{i}(t)+S_{i}(t) * p s_{i}(t)+C_{i}(t) * p c_{i}(t)\right)+\alpha *$

$\left.\left(r+\gamma * E_{i j}(t) * p e_{i}(t)+S_{i}(t) * p s_{i}(t)+C_{i}(t) * p c_{i}(t)\right)\right]$

The Shapley Value $S_{i}(t)$ is used to measure the expectation of how much an organization can gain if it belongs to that alliance. Let a set of n companies $v=\left\{V_{1}, \ldots, V_{n}\right\}$, the function gain $v($.$) , and the subset S \subseteq v$ [11]. The Shapley value is computed taking into account the value each company gains for being in the cooperation:

$$
S_{i}(v)=\sum_{S \subseteq v} \frac{|S| !(|v|-|S|-1) !}{|v| !}\left(v\left(S \cup\left\{V_{i}\right\}\right)-v(S)\right)
$$

The impact of the alliance on the organization is given by the influence that affects the agent in its decision making. Organizations decide to remain (or not) in the alliance based on growth and on the impact of the alliance. If the organization is growing and has the expectation to improve its results for belonging to the alliance, then the organization will remain. When the organization is not growing and does not expect to have better results, then, it will go out of the alliance. If the organization has different indicators from the growth and the impact of the alliance, then the organization will evaluate what to do in the next period. In the case when a positive change happens then the organization stay, otherwise it exits. We assume that there is convergence in the flocking, when the organizations give the same reward in $80 \%$ of time, in two different iterations of the algorithm. Exits and the permanence rate of the alliance are given by equations 2 and 3, respectively.

$$
\begin{gathered}
\text { Exits }=\frac{\text { initial number of organizations }- \text { final number of organizations }}{\text { initial number or organizations }} \\
\text { Permanence rate of the alliance }=(1-\text { Exits }) * 100
\end{gathered}
$$

\section{$4 \quad$ Results}

The AllFlock model that was created to simulate the flocking behavior has been developed in Netlogo [16].

Table 2. Configurartions and Combination of parameters

\begin{tabular}{c|ccccc}
\hline & \multicolumn{5}{|c}{ Parameters (given by the user) } \\
\cline { 2 - 6 } & $\begin{array}{c}\text { Initial number } \\
\text { of organiza- } \\
\text { tions }\end{array}$ & $\begin{array}{c}\text { Exploration rate } \\
\text { vs. knowledge } \\
\text { (Sigma) }\end{array}$ & Delta & Discount & $\begin{array}{c}\text { Evaluation } \\
\text { time } \\
\text { (time) }\end{array}$ \\
\hline Configuration 1 & Low & Low & High & High & Low \\
Configuration 2 & Low & Low & High & High & High \\
Configuration 3 & Low & Low & High & Moderate & High \\
Configuration 4 & Low & Moderate & High & High & Low \\
Configuration 5 & Low & Moderate & High & High & High \\
\hline
\end{tabular}


The final results are the average of the 100 simulations for different number of iterations. In the analysis of the five configurations, the evidence of convergence has the highest value at configuration 2, with the average of 106 iterations. The configuration that presents, on average, a fewer iterations occurs in the configuration 4 . A Kruskal Wallis test was applied to verify if the distribution of iterations is the same between the configuration categories, as the permanence rate and the growth rate. The null hypothesis was rejected for a significance level of 0.05 in all three situations. Four different instants of simulation are possible to observe at Fig. 1.
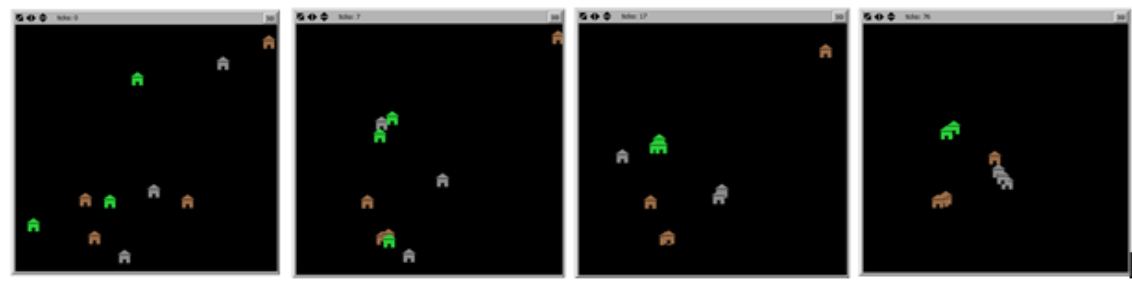

Fig. 1. Organizations behavior at four different instants of simulation (instants $0,7,17$ e 76 ) for configuration 5 (Netlogo screenshots).

As we can observe at Fig. 2 the highest average permanence rate by alliance occurs at Configuration 2 with $78.81 \%$, with $81.72 \%$ at Configuration 3 and at Configuration 5 with $80.92 \%$ and $79.73 \%$. The lowest average permanence rate by alliance occurs at Configuration 1 with $54.95 \%$ and at Configuration 4 with $53.42 \%$. Average permanence rate between alliances in same configuration is not much different, in some cases is very close as in the alliances at Configuration $1(54.95 \%, 57.62 \%$ and $56.08 \%)$ and between the Alliance0 and Alliancel at Configuration $4(59.27 \%$, $59.37 \%$ and $53.42 \%)$.

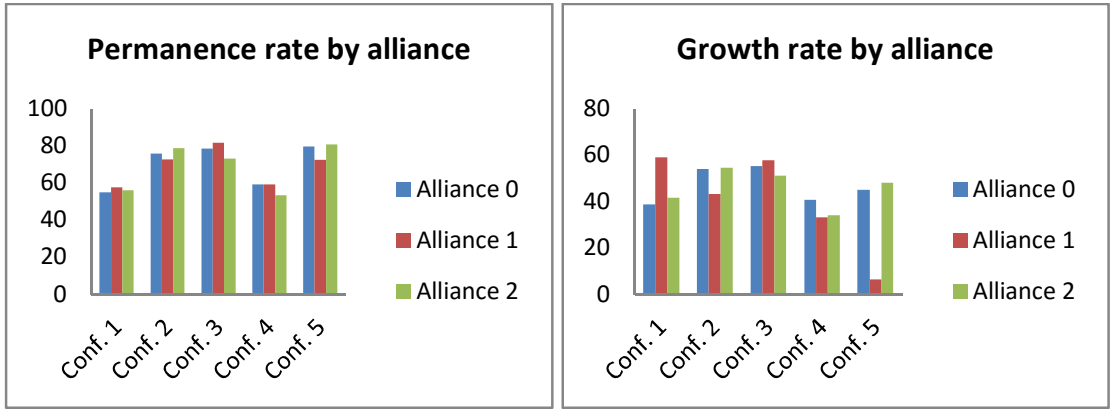

Fig. 2. Average permanence rate and average growth rate by alliance, for each configuration.

Average growth rate between alliances for Configuration $3(55.26 \%, 57.78 \%$ and $51.11 \%)$ and Configuration $4(40.77 \%, 33.34 \%$ and $31.10 \%)$ are very close, as is possible to observe at Fig. 2. The same does not happen in Configurations 1, 2 and 5. 
In Configuration 1 the average growth rate by alliance is $38.83 \%, 59.17 \%$ and $41.65 \%$, the average growth rate by alliance is $54.11 \%, 43.26 \%$ and $54.53 \%$ at Configuration 2, and for Configuration 5 with $45.11 \%, 6.37 \%$ and $48.14 \%$. Average growth rate by alliance has the lowest value, $6.37 \%$, at alliance 1 in Configuration 5 and the highest value for the same alliance at Configuration 1.

Best result for average permanence rate by alliance with simulated data, using expression (4), occurs at Alliance0 with a rate of $69.69 \%$. The highest value in the air transport alliances, with real data, for the average permanence rate by alliance can be observed at SkyTeam alliance which has a rate of $79.17 \%$. Oneworld has the lowest value with an average permanence rate of $75 \%$ and StarAlliance has an average permanence rate of $75.68 \%$. In the results for simulated data, (for which there is no correspondence with real data), the maximum number or organizations is in the initial instant.

\section{Conclusions}

Inspired on three $\mathrm{C}-\mathrm{S}$ algorithm concepts: the position, velocity and influence, we used the same ideas concepts not always nearby, as in the case of the position and influence to construct the AllFlock model. The AllFlock model (Flocking in Strategic Alliances) proposed in this paper intends to recreate the way as organizations act in order to analyze it in terms of flocking behavior. We observed the evidence of convergence (existence of flock behavior).

In some configurations, such as, configuration 1 and configuration 4 companies remain in average less time in alliances, which can be explained by their need for good results ("time").Was also observed that the average of permanence rate is closer between alliances than the average growth rate, which may be an indication of heterogeneous growth between companies. The AllFlock model does not allow for an organization to leave from an alliance and change to another. In addition, it does not consider other possibilities of sub-collaborations inside the companies of the alliance.

These are limitations of the AllFlock which are being considered for future work. With this evidence of flock behavior in strategic alliances, an analysis of typologies can be improved in future work (since there is some evidence that some typologies can be related with some parameters of simulation, like "time").

The proposed model can be seen as a first step to understanding the collective intelligence in organizations, namely in airline industries, by using flocking behavior.

\section{References}

1. Beni, G., Wang, J. (1989). Swarm Intelligence in Cellular Robotic Systems, Proceed. NATO Advanced Workshop on Robots and Biological Systems.

2. Camarinha-Matos, L.M., Afsarmanesh, H. (2005). Collaborative networks: A new scientific discipline. J. Intelligent Manufacturing 16(4-5), 439-452.

3. Cucker, F. and Smale, S. (2007a). Emergent behavior in flocks. IEEE Transactions on Automatic Control, 52(5), 852-862. 
4. Cucker, F. and Smale, S. (2007b). On the mathematics of emergence. Japanese Journal of Mathematics, 2(1), 197-227.

5. Evans, N. (2001). Collaborative strategy: an analysis of the changing world of international airline alliances, Tourism Management,22: 229-43.

6. Fehr, E. and Urs Fischbacker. (2002). "Why social preferences matter: the impact of nonselfish motives on competition, cooperation, and incentives". Economic Journal 112 (478): C1-33.

7. Fernandez de la Torre, Pablo E. (1999) "Airline alliances: the airline perspective". DSpace@MIT. Retrieved from http://hdl.handle.net/1721.1/68159

8. Johnson, G., Whittington, R., Scholes, K., Angwin, D., P. R. (2014). Exploring Strategy (10 ${ }^{\mathrm{a}}$ edition). Harlow: Pearson. ISBN 978-1-292-00255-2.

9. Lévy, P. (1997). Collective Intelligence: Mankind's Emerging World in Cyberspace. Challenges. Perseus Books. Retrieved from http://portal.acm.org/citation.cfm?id=550283

10. Olfati-Saber, R. (2006). Flocking for multi-agent dynamic systems: Algorithms and theory. IEEE Transactions on Automatic Control, 51(3), 401-420.

11. Papapetrou, P., Gionis, A. and Mannila, H. (2011). A Shapley value approach for influence attribution. In Lecture Notes in Computer Science (including subseries Lecture Notes in Artificial Intelligence and Lecture Notes in Bioinformatics). doi:10.1007/978-3-64223783-6_35.

12. Reynolds, C. W. (1987). Flocks, herds and schools: A distributed behavioral model. ACM SIGGRAPH Computer Graphics.

13. Salminen, J. (2012). Collective Intelligence in Humans: a Literature Review. Arxiv Preprint arXiv12043401, abs/1204.3, 1 - 8. Retrieved from http://arxiv.org/abs/1204.3401

14. Shapley, L. S. (1953). A Value for n-person Games. Annals of Mathematics Studies, 28, 307-317.

15. Sutton, R. S. and Barto, A. G. (1998). Reinforcement Learning: An Introduction. Bradford Books, MIT Press, Cambridge, MA, 2002 edition.

16. Vicsek, T., Czirok, A., Ben-Jacob, E., Cohen, I. e Shochet, O. (1995). Novel type of phase transition in a system of self-driven particles. Physical Review Letters, 75(6), 1226-1229.

17. Wilensky, U., \& Rand, W. (2015). An introduction to agent-based modeling: Modeling natural, social and engineered complex systems with NetLogo. Cambridge, MA: MIT Press. 